\title{
RESEARCH
}

Open Access

\section{CILP2 overexpression correlates with tumor progression and poor prognosis in patients with colorectal cancer in The Cancer Genome Atlas (TCGA) study}

Feng Huang ${ }^{1}$, Yuanfei Peng ${ }^{2}$, Qing Ye ${ }^{1 *}$, Jinhu Chen ${ }^{1}$, Yangming $\mathrm{Li}^{1}$, Shengyuan Liu', Yangmei $\mathrm{Xu}^{1}$ and Lijie Huang ${ }^{1}$

\begin{abstract}
Background: Genetic alterations play an important role in the progression of colorectal cancer (CRC). Identifying new biomarkers to assess the prognosis of patients with CRC is critical. Cartilage intermediate layer protein 2 (CILP2) gene, screened from TCGA database by bioinformatics, may be closely related to the progression of CRC. CILP2 was barely reported with clinical features of tumors.

Materials and methods: Clinical information and RNA-seq data were derived from TCGA colorectal carcinoma cohort. CILP2 expression at mRNA level was estimated by bioinformatical analysis of TCGA cases. Tissue microarray (TMA) was constructed containing paraffin-embedded 64 pairs of CRC and matched adjacent normal tissues. The expression at the protein level was detected in 64 pairs of CRC and matched adjacent normal tissues by immunohistochemical analysis. CILP2 expression level and its clinical value were estimated by bioinformatical analysis with linear and logistic regression. Survival analysis was performed between high and low groups of CILP2 expression by Cox regression analysis, and the $P$ value was calculated by the log-rank test. The Kaplan-Meier curves were tested by the log-rank test.

Results: CILP2 was statistically significantly higher expressed in the CRC tissues when compared with paired adjacent normal tissues in TCGA cohort $(P<0.001)$ and in the TMA cohort $(P=0.001)$. Also, CILP2 high expression was strongly correlated with T3/4 stage $(P=0.001), \mathrm{N} 1 / 2 / 3$ stage $(P=0.005)$, M1 stage $(P=0.048)$, and higher clinical stage (UICC 2010 stage) $(P<0.001)$ in TCGA cohort, and also positively associated with T3/4 stage $(P=0.022)$ and higher clinical stage (UICC 2010 stage) $(P=0.03)$ in TMA cohort. Furthermore, CILP2 overexpression predicted poor prognosis and could be an independent prognostic factor $(P=0.003)$.
\end{abstract}

Conclusion: We revealed that CILP2 is associated with advanced stages and could play a role as an independent predictor of poor survival in CRC.

Keywords: CILP2, Colorectal cancer, TCGA, Immunohistochemistry, Prognosis

\footnotetext{
* Correspondence: yabobo@163.com

'Department of Gastrointestinal Tumor Surgery, Fujian Cancer Hospital \& Fujian Medical University Cancer Hospital, Fujian Province Key Laboratory of Tumor Biotherapy, No. 420 Fuma Road, Fuzhou ,350014, Fujian Province, People's Republic of China

Full list of author information is available at the end of the article
}

(c) The Author(s). 2020 Open Access This article is licensed under a Creative Commons Attribution 4.0 International License, which permits use, sharing, adaptation, distribution and reproduction in any medium or format, as long as you give appropriate credit to the original author(s) and the source, provide a link to the Creative Commons licence, and indicate if changes were made. The images or other third party material in this article are included in the article's Creative Commons licence, unless indicated otherwise in a credit line to the material. If material is not included in the article's Creative Commons licence and your intended use is not permitted by statutory regulation or exceeds the permitted use, you will need to obtain permission directly from the copyright holder. To view a copy of this licence, visit http://creativecommons.org/licenses/by/4.0/. The Creative Commons Public Domain Dedication waiver (http://creativecommons.org/publicdomain/zero/1.0/) applies to the data made available in this article, unless otherwise stated in a credit line to the data. 


\section{Introduction}

Colorectal cancer (CRC) is one of the most common cancers that ranks second in cancer-associated mortality in the world, with increasing morbidity in recent years. It was estimated that in 2018, more than 1.8 million new cases occurred with 881,000 deaths [1]. CRC is caused by a variety of factors and is involved in the successive accumulation of genetic and epigenetic alternations [2]. Surgical resection is the mainstay for the treatment of CRC, but tumor recurrence is common. A large cohort study indicated that the median survival time was 13.3 months before recurrence [3]. Numerous works have been done to reveal the underlying mechanisms of $\mathrm{CRC}$, and encouraging progress has been made [4-7]. However, further investigating works are still needed to deeply understand the molecular mechanisms, and molecular biomarkers for both early detection and prognosis are to be developed for better therapeutic uses in the patients.

The Cancer Genome Atlas (TCGA) is a comprehensive cancer research project initiated by the National Cancer Institute (NCI) and the National Human Genome Research (NHGRI). By applying genome analysis technology, especially the large-scale genome sequencing technology, TCGA draws the map of 33 kinds of multiple human tumor genome variation, including $631 \mathrm{CRC}$ samples. We screened the CLIP2 gene from TCGA CRC database by bioinformatics techniques. CILP2, highly cognate with CILP1, is a secreted glycoprotein that has been first isolated from human articular cartilage. Mesenchymal protein (CILPs) plays an important role in cartilage support and is associated with the occurrence of osteoarthritis. A significant association was also highlighted between polymorphisms in the CILP gene and osteoarthritis progression [8]. The CILP gene is located on chromosome 19p13. It was reported that through genomewide association studies (GWAS), the neurocan-cartilage intermediate layer protein 2-pre-B cell leukemia homeobox 4 (NCAN-CILP2-PBX4) region, an intergenic region spanning $300 \mathrm{~kb}$, is associated with concentrations of low-density lipoprotein cholesterol and triglycerides in sera [9]. Eleven genes and one miRNA are encoded in this region. This region has been shown to be consistent and has deep association with serum lipid levels in subsequent studies for individuals of European and Chinese descents [10-12]. In addition to plasma lipid levels, the genome region around CILP2 was identified as a non-alcoholic fatty liver disease (NAFLD)-associated locus by GWAS in individuals of European descent [13], but not in Japanese individuals [14].

Tumors have been considered as high demands of energy and abnormal anabolism for their rapid growth. In recent years, many studies have found that tumor development is often accompanied by metabolic abnormalities, and lipid mass spectrometry and lipid metabolism abnormalities play a particularly important role in this process [15]. But subtle mechanisms underlying over- reacted lipid metabolism remain poorly understood. In the preliminary study of TCGA and our cohort analysis, we found that CLIP2 gene showed a tendency of upexpression in CRC tissues compared with other genes screened by bioinformatics from TCGA CRC database. Besides, few reports have described the relationship between CILP2 and cancers, except one that reported an expression quantitative trait locus, namely rs8103992, was statistically significantly associated with osteosarcoma risk [16]. In this study, we evaluated CILP2 expression and its correlations with clinicopathological characteristics, such as tumor stages, and overall survival of CRC patients in TCGA, and furtherly verified using immunohistochemistry assay within human CRC tissues, which may provide a new potential molecular marker for prognostic use of the patients.

\section{Materials and methods}

\section{TCGA data mining and gene expression datasets}

The CRC cohort in TCGA was downloaded, and level 3 RNA-seq V2 datasets were used, which was based on Illumina HiSeq 2000. Matched clinical data from CRC patients were also downloaded (https://portal.gdc.cancer. gov/). In the cohort, 621 patients were included, and 609 among them had intact survival data recorded. So, 609 patients were included in the survival analysis in the study. For each gene, the transcript with the highest expression was selected for the following process. Meanwhile, the data of one gene was considered invalid when raw counts of the gene in all samples were less than 50 . All filtered gene expressions had been processed and been normalized by trimmed mean of $M$ values analysis.

\section{Tissue microarray construction}

Tissue microarray (TMA) construction was carried out as described previously [17]. Briefly, 64 pairs of CRC and matched adjacent normal tissues were obtained from patients undergoing surgery between January 2016 and October 2019 at the Department of Gastrointestinal Tumor Surgery, Fujian Cancer Hospital. TMA recipient block was constructed containing paraffin-embedded 64 pairs of tumor and matched adjacent normal tissues previously fixed in $10 \%$ formaldehyde. The most representative tumor or normal areas were carefully selected and marked based on the matched hematoxylin-eosin-stained slides. Altogether, 128 cores (diameter $1.8 \mathrm{~mm}$ ) of test tissue were taken from the donor blocks with the tissue microarrayer (Beecher Instruments, Silver Spring, MD, USA) and inserted into the recipient block.

\section{Immunohistochemistry analysis}

Immunohistochemistry was carried out as described previously [17]. Briefly, unstained 4-mm sections were cut from the TMA recipient block and deparaffinized in 
xylene, and the slides were bathed in $0.01 \mathrm{~mol} / \mathrm{l}$ sodium citrate and heated in a microwave oven for $12 \mathrm{~min}$. The sections were incubated with anti-CILP2 antibody (Santa Cruz, CA, USA) and kept at $4{ }^{\circ} \mathrm{C}$ overnight. Negative control slides were treated with only non-immunized mouse immunoglobulin fraction under equivalent conditions. For the secondary developing reagents, a labeled streptavidin-biotin kit (Dako, CA, USA) was used. Slides were developed with diaminobenzaminidine and counterstained with hematoxylin.

\section{Evaluation of immunostaining results}

Immunohistochemistry staining was scored as described previously blindly by two independent pathologists without knowledge of the patient's clinicopathology and clinical outcome $[18,19]$. Positive cases were defined by the presence of intracellular staining with red/brown color in epithelial cells. The expression level of CILP2 was evaluated semi-quantitatively according to the proportion of positively stained tumor cells for CILP2 and the intensity of the staining. The staining intensity ranged between 0 and 3 as follows: (I) 0 , no recognizable staining, referred to as negative (-); (II) 1, slight staining, referred to as weakly positive (+); (III) 2 , moderate staining, referred to as moderately positive (++); and (IV) 3 , distinct staining, referred to as strongly positive $(+++)$. The staining percentage was evaluated as follows: $0-10 \%=1,11-50 \%=$ $2,50-75 \%=3$, and $75-100 \%=4$. The immune scores of each patient were calculated by the addition of intensity and percentage together. According to the protein of CILP2 expression, samples were divided into two groups, immune scores greater than or equal to 4 were defined as high expression, and immune scores less than 4 were defined as low expression.

\section{Statistical analysis}

Statistical analyses were performed using SPSS 22.0 software. CILP2 gene expression in different groups (divided by each parameter) was compared using the MannWhitney $U$ test. Correlation between CILP2 gene expression and different TNM stages was analyzed by Spearman's test, and Spearman's rank correlation coefficient $\left(r_{s}\right)$ was used to evaluate the strength of association. CILP2 gene expression in different groups was analyzed by one-way ANOVA followed by Welch's $t$ test. CILP2 protein expression in different groups was analyzed by Fisher's exact test. Survival analysis was performed between high and low groups of CILP2 expression (defined by the median value of CILP2 expression) by Cox regression analysis, and the $P$ value was calculated by the log-rank test. The Kaplan-Meier curves were tested by the log-rank test.

\section{Results}

CILP2 was overexpressed in CRC

Aiming at searching for potential novel prognostic markers of CRC, we firstly analyze expression data of TCGA CRC cohort from Illumina HiSeq 2000 platform, which contains 621 samples and correlating clinical and demographic information. We found that CILP2 was strongly correlated with clinical features of the samples in TCGA cohort, and CILP2 has not been reported in CRC before. So we focused on CILP2 and furtherly analyzed the association between CILP2 expression and CRC prognosis. To determine the role of CILP2 in CRC, we first analyzed CILP2 gene expression in 50 patients' samples with paired adjacent normal tissues in TCGA cohort, and the results suggested that CILP2 gene was overexpressed statistically significant in tumor samples compared to paired adjacent normal tissues (Fig. 1a, b; fold change $=3.412 ; P<0.001 ;$ Table 1 ). Additionally, CILP2 gene expression was upregulated in the total amount of tumor samples compared with adjacent normal tissue samples in TCGA cohort (Fig. 1c, fold change $=8.6161, P<0.001$, Table 1$)$.

To further testify the upregulation of CILP2 in CRC, we detected CILP2 protein expression in a TMA $(n=$ 64) by immunohistochemical staining (IHC). We found that $68.75 \%(44 / 64)$ of tumor tissues highly expressed CILP2 protein, whereas only $39.06 \%$ (25/64) of matched adjacent normal tissues highly expressed CILP2 protein. The staining result in our cohort showed that CILP2 protein expression was statistically significantly more prevalent in tumors than in matched adjacent normal tissues (Fig. $1 \mathrm{~d}, P=0.001$ ). The representative images of CILP2 immunostaining are shown in Fig. 1e, f.

\section{Correlations between CILP2 expression and clinicopathological parameters in CRC}

Furthermore, to dissect the role of CILP2 in CRC carcinogenesis, correlations between CILP2 expression and clinicopathological parameters were analyzed based on TCGA cohort (mRNA) and TMA cohort (protein), presented in Table 2. And Table 3 shows the correlation analysis results of TCGA cohort using Spearman's test. Among 621 samples from TCGA cohort, part of the clinicopathological data was missed in some cases. Median expression of CILP2 of all samples was chosen as a cutoff to divide samples into the CILP2-high $(n=310)$ group and CILP2-low $(n=311)$ group. We observed that in TCGA cohort, tumors of high CILP2 expression were positively associated with the T3/4 stage (T1/2, 36.51\%; T3/4, 53.35\%; $P=0.001$, Table 2) and with the N1/2/3 stage (N0, 44.89\%; N1/2/3, 74.29\%; $P=0.005$, Table 2). Similarly, the percentage of tumors with high CILP2 expression increased with grading of clinical stage (UICC 2010 stage) (stage I, 34.29\%; stage II, 49.35\%; stage III, 
A.

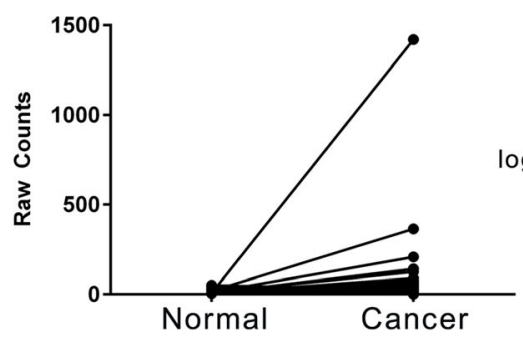

C.

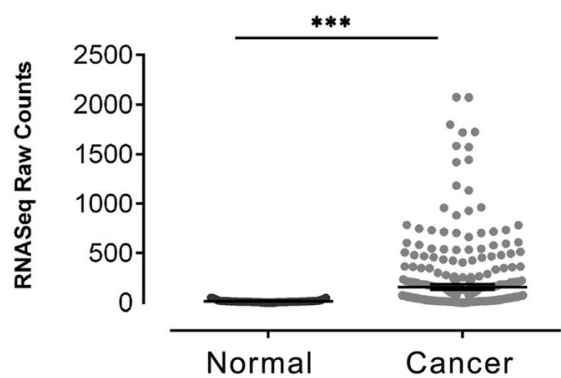

B.

D.
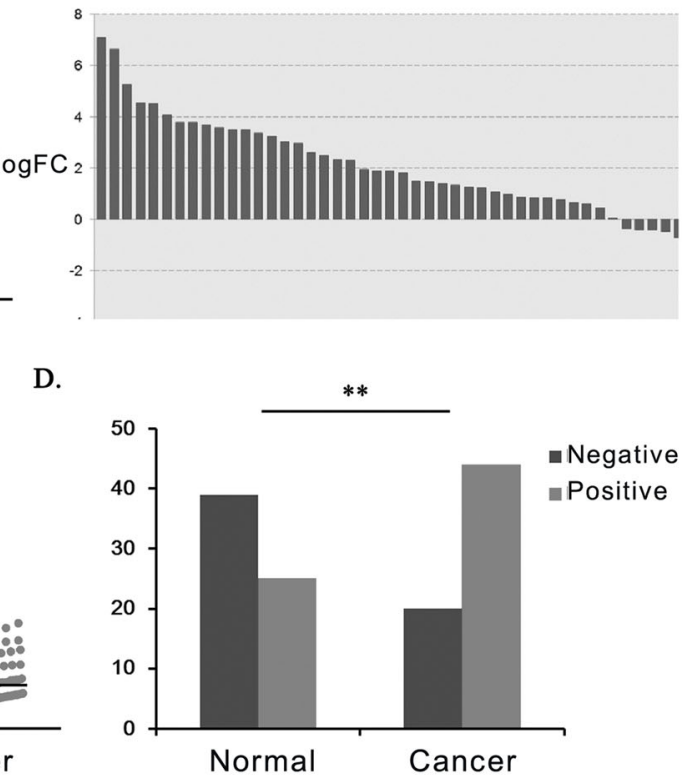

E.

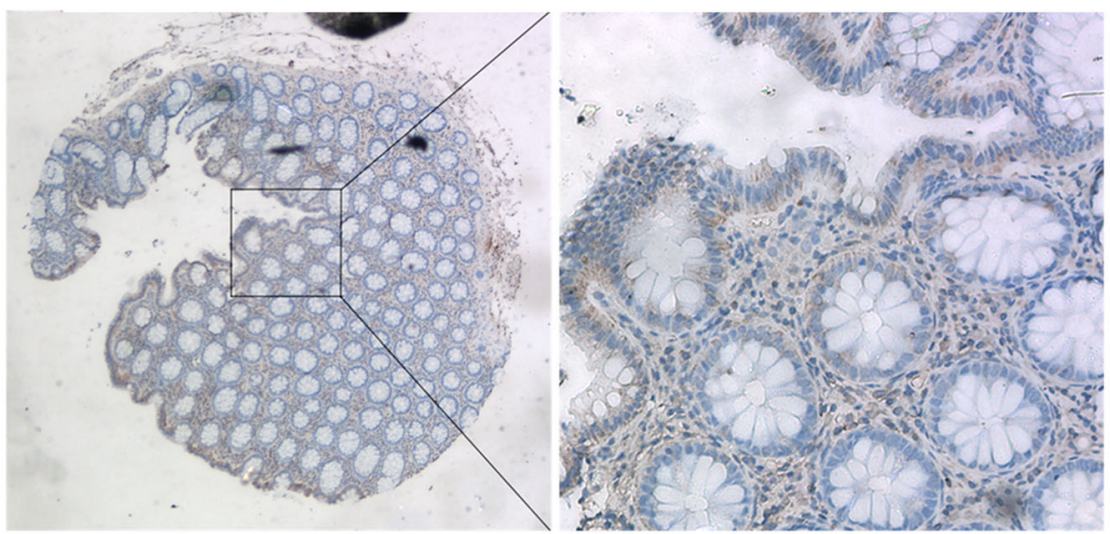

F.

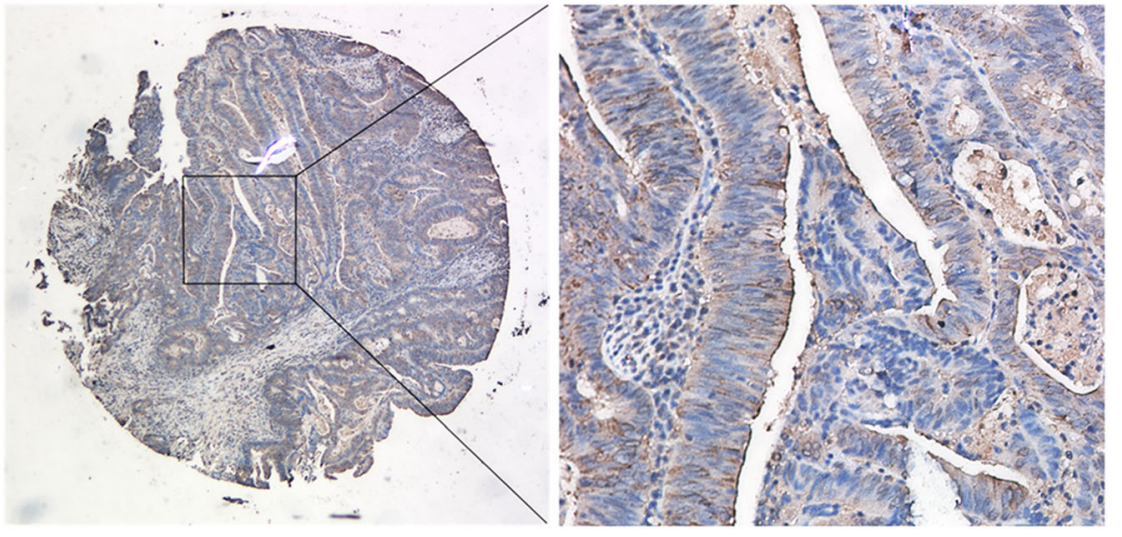

Fig. 1 CILP2 was upregulated in colorectal cancer samples. a, b The line chart and histogram of CILP2 gene expression in 50 paired tumor and matched adjacent normal tissue samples in TCGA cohort. FC, fold change. c Scatter plot of CILP2 expression in all normal and cancer samples in TCGA cohort. ***P< 0.001. d Positive or negative expression of CILP2 protein in matched adjacent normal tissues (normal) or cancer tissues in the TMA cohort. ${ }^{* *} P=0.001$. e Representative image of normal tissue immunohistochemical staining in the TMA cohort. Left: original magnification $\times 100$; right: original magnification $\times 400$. $\mathbf{f}$ Representative image of cancer tissue immunohistochemical staining in the TMA cohort. Left: original magnification $\times 100$; right: original magnification $\times 400$ 
Table 1 CILP2 gene expression in 50 paired tumor and matched adjacent normal tissue samples, and in all normal and cancer samples in TCGA cohort

\begin{tabular}{lllllllll}
\hline & ID & Gene symbol & FC & $\boldsymbol{P}$ value & Total sample & Sample unchanged & Sample up & Sample down \\
\hline Paired samples & 148113 & CILP2 & 3.412 & $2.56 \mathrm{E}-07$ & 50 & 15 & 31 & 4 \\
Total samples & 148113 & CILP2 & 8.6161 & $1.28 \mathrm{E}-19$ & 621 & - & - & - \\
\hline
\end{tabular}

54.19\%; stage IV, 60.00\%; $P<0.001$, Table 2) and distant metastasis (M0, 48.69\%; M1, 60.23\%; $P=0.048$, Table 2). It was suggested that CILP2 gene expression was strongly correlated with $\mathrm{T}$ stage $(P=0.001), \mathrm{N}$ stage $(P$ $=0.005), \mathrm{M}$ stage $(P=0.048)$, and higher clinical stage $(P<0.001)$, respectively, in TCGA cohort (Fig. 2$)$. However, there was no significant correlation of CILP2 expression with patients' age or gender $(P>0.05$, Table 2$)$. In TMA cohort, tumors of positive CILP2 protein expression was statistically significantly associated with T3/4 stage (T1/2, 44.83\%; T3/4, 74.29\%; $P=0.022$, Table 2) and higher clinical stage (UICC 2010 stage) (stage I, $35.71 \%$; stage II, $50.00 \%$; stage III, $70.83 \%$; stage IV, $90.00 \% ; P=0.03$, Table 2). However, there was no significant correlation of CILP2 protein expression with $\mathrm{N}$ stage $(P=0.2$, Table 2$)$; it may be due to a limited set of data. Although the significant correlation was also not reached in our cohort, there was a tendency that tumors with positive CILP2 protein expression were more likely to distantly metastasize compared with CILP2-negative tumors $(P=0.074$, Table 2$)$.

\section{High CILP2 expression is associated with poor outcome of CRC patients}

The Kaplan-Meier analysis was performed to investigate the relationship between CILP2 expression and overall survival in TCGA cohort. There were 609 CRC samples available for prognostic information. Median expression of CILP2 of all samples was chosen as a cutoff to divide samples into the CILP2-high $(n=305)$ group and CILP2-low $(n=304)$ group. As shown in Fig. 3 and Table 4, CRC patients with high CILP2 expression exhibited a poorer

Table 2 Association between CILP2 expression level and clinicopathological parameters in CRC patients

\begin{tabular}{|c|c|c|c|c|c|c|}
\hline \multirow{2}{*}{$\begin{array}{l}\text { Clinicopathological } \\
\text { parameters }\end{array}$} & \multicolumn{3}{|c|}{ Expression of CILP2 mRNA in TGCA } & \multicolumn{3}{|c|}{ Expression of CILP2 protein in TMA cohort } \\
\hline & High $(n=310)$ & Low $(n=311)$ & $P$ value & High $(n=39)$ & Low $(n=25)$ & $P$ value \\
\hline Age (years) & & & 0.059 & & & 0.37 \\
\hline$\leq 68(n=331)$ & 177 (53.47\%) & $154(46.53 \%)$ & & $20(66.67 \%)$ & $10(33.33 \%)$ & \\
\hline$>68(n=290)$ & $133(45.86 \%)$ & $157(54.14 \%)$ & & 19 (55.88\%) & $15(44.12 \%)$ & \\
\hline Gender & & & 0.400 & & & 0.8 \\
\hline Male $(n=331)$ & $160(48.34 \%)$ & $171(51.66 \%)$ & & $22(62.86 \%)$ & $13(37.14 \%)$ & \\
\hline Female $(n=290)$ & $150(51.72 \%)$ & $140(48.28 \%)$ & & $17(58.62 \%)$ & $12(41.38 \%)$ & \\
\hline Pathological T stage ${ }^{a}$ & & & 0.001 & & & 0.022 \\
\hline $\mathrm{T} 1 / 2(n=126)$ & $46(36.51 \%)$ & $80(63.49 \%)$ & & $13(44.83 \%)$ & $16(55.17 \%)$ & \\
\hline $\mathrm{T} 3 / 4(n=493)$ & $263(53.35 \%)$ & $230(46.65 \%)$ & & $26(74.29 \%)$ & $9(25.71 \%)$ & \\
\hline$N$ stage $^{a}$ & & & 0.005 & & & 0.2 \\
\hline NO $(n=352)$ & $158(44.89 \%)$ & 194 (55.11\%) & & $16(51.61 \%)$ & $15(48.39 \%)$ & \\
\hline $\mathrm{N} 1 / 2 / 3(n=265)$ & 149 (56.23\%) & 116 (43.77\%) & & $23(69.70 \%)$ & $10(30.30 \%)$ & \\
\hline M stage ${ }^{a}$ & & & 0.048 & & & 0.074 \\
\hline $\mathrm{MO}(n=458)$ & 223 (48.69\%) & $235(51.31 \%)$ & & $30(55.56 \%)$ & 24 (44.44\%) & \\
\hline M1 $(n=88)$ & $53(60.23 \%)$ & 35 (39.77\%) & & $9(90.00 \%)$ & $1(10.00 \%)$ & \\
\hline Clinical stage $e^{a}$ & & & $<0.001$ & & & 0.03 \\
\hline Stage I $(n=105)$ & 36 (34.29\%) & 69 (65.71\%) & & $5(35.71 \%)$ & $9(64.29 \%)$ & \\
\hline Stage II $(n=229)$ & 113 (49.35\%) & $116(50.65 \%)$ & & $8(50.00 \%)$ & $8(50.00 \%)$ & \\
\hline Stage III $(n=179)$ & 97 (54.19\%) & $82(45.81 \%)$ & & 17 (70.83\%) & $7(29.17 \%)$ & \\
\hline Stage IV $(n=90)$ & $54(60.00 \%)$ & $36(40.00 \%)$ & & $9(90.00 \%)$ & $1(10.00 \%)$ & \\
\hline
\end{tabular}

$P$ value $<0.05$ was considered statistically significant (in bold). $T$ tumor, $N$ regional lymph node, $M$ metastasis 
Table 3 Correlation between CILP2 expression and TNM stages in CRC patients in TCGA cohort

\begin{tabular}{|c|c|c|c|c|c|c|}
\hline & & CILP2 expression & T stage & N stage & M stage & Clinical stage \\
\hline \multirow[t]{2}{*}{ CILP2 expression } & $r_{s}^{2}$ & 1.000 & 0.136 & 0.112 & 0.085 & 0.149 \\
\hline & $P$ (two-tailed) & N.A & 0.001 & 0.005 & 0.048 & $<0.001$ \\
\hline \multirow[t]{2}{*}{ T stage } & $r_{s}^{2}$ & 0.136 & 1.000 & 0.308 & 0.197 & 0.589 \\
\hline & $P$ (two-tailed) & 0.001 & N.A & $<0.001$ & $<0.001$ & $<0.001$ \\
\hline \multirow[t]{2}{*}{ N stage } & $r_{s}^{2}$ & 0.112 & 0.308 & 1.000 & 0.418 & 0.846 \\
\hline & $P$ (two-tailed) & 0.005 & $<0.001$ & N.A & $<0.001$ & $<0.001$ \\
\hline \multirow[t]{2}{*}{ M stage } & $r_{s}^{2}$ & 0.085 & 0.197 & 0.418 & 1.000 & 0.665 \\
\hline & $P$ (two-tailed) & 0.048 & $<0.001$ & $<0.001$ & N.A & $<0.001$ \\
\hline \multirow[t]{2}{*}{ Clinical stage } & $r_{s}^{2}$ & 0.149 & 0.589 & 0.846 & 0.665 & 1.000 \\
\hline & $P$ (two-tailed) & $<0.001$ & $<0.001$ & $<0.001$ & $<0.001$ & N.A \\
\hline
\end{tabular}

$P$ value $<0.05$ was considered statistically significant (in bold). $T$ tumor, $N$ regional lymph node, $M$ metastasis

overall survival rate compared with the low-expression group $(P=0.003)$. Moreover, the univariate Cox regression analysis indicated that high CILP2 expression was strongly associated with a poor prognosis $(P=0.003)$. Other clinical variables, such as age $(P<0.0001)$, T stage $(P=0.005), \mathrm{N}$ stage $(P<0.0001), \mathrm{M}$ stage $(P<0.0001)$, and clinical stage (UICC 2010 stage) $(P<0.0001)$, were all associated with overall survival (Table 5). Moreover, the multivariate analysis revealed that high CILP2 expression $(P=0.034)$, age $(P<0.0001)$, $M$ stage $(P<0.0001)$, and clinical stage (UICC 2010 stage) $(P=0.017)$ were independently associated with a poor prognosis (Table 5 ).

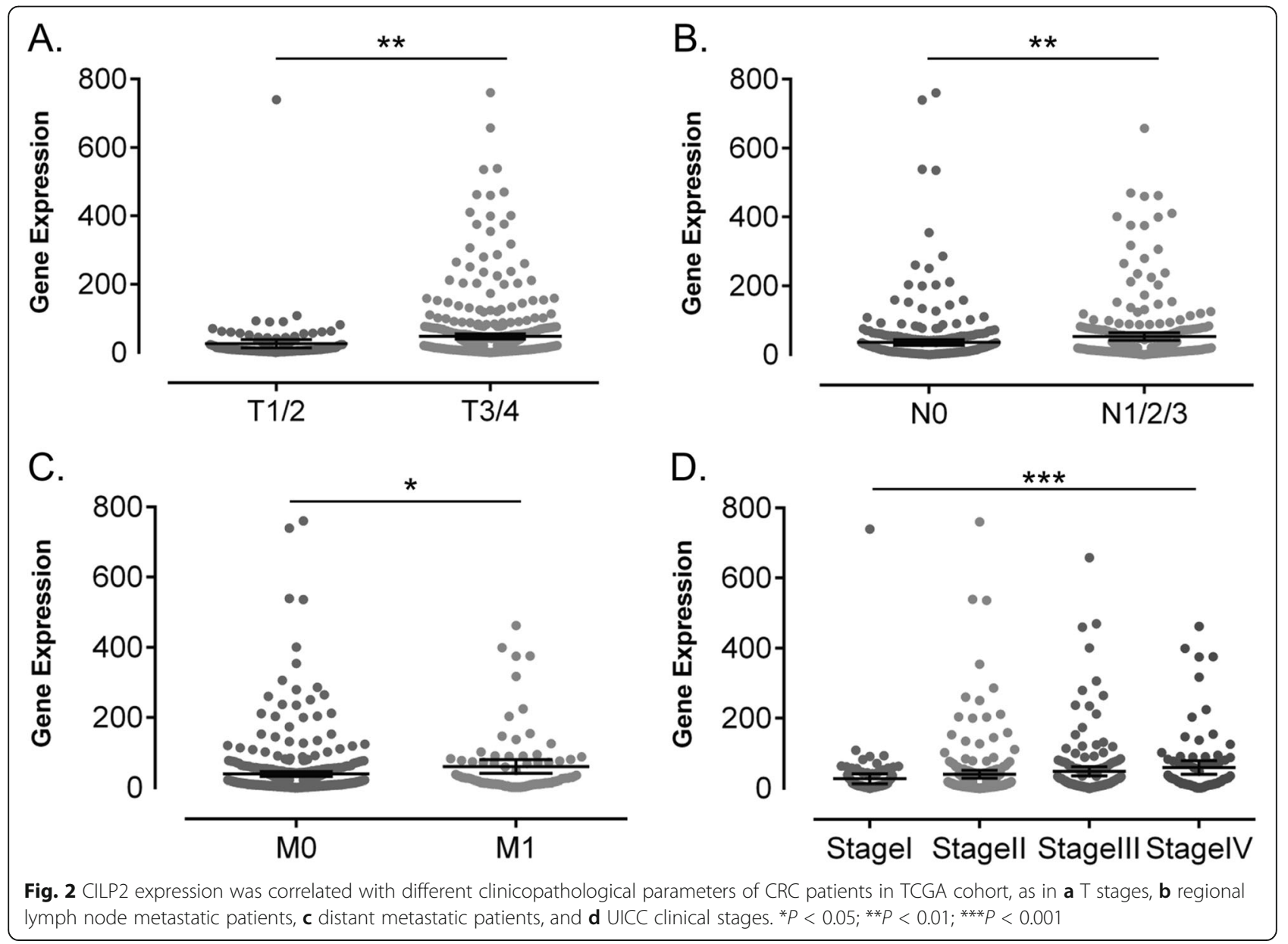




\section{Survival proportions: Survival of Two Groups}

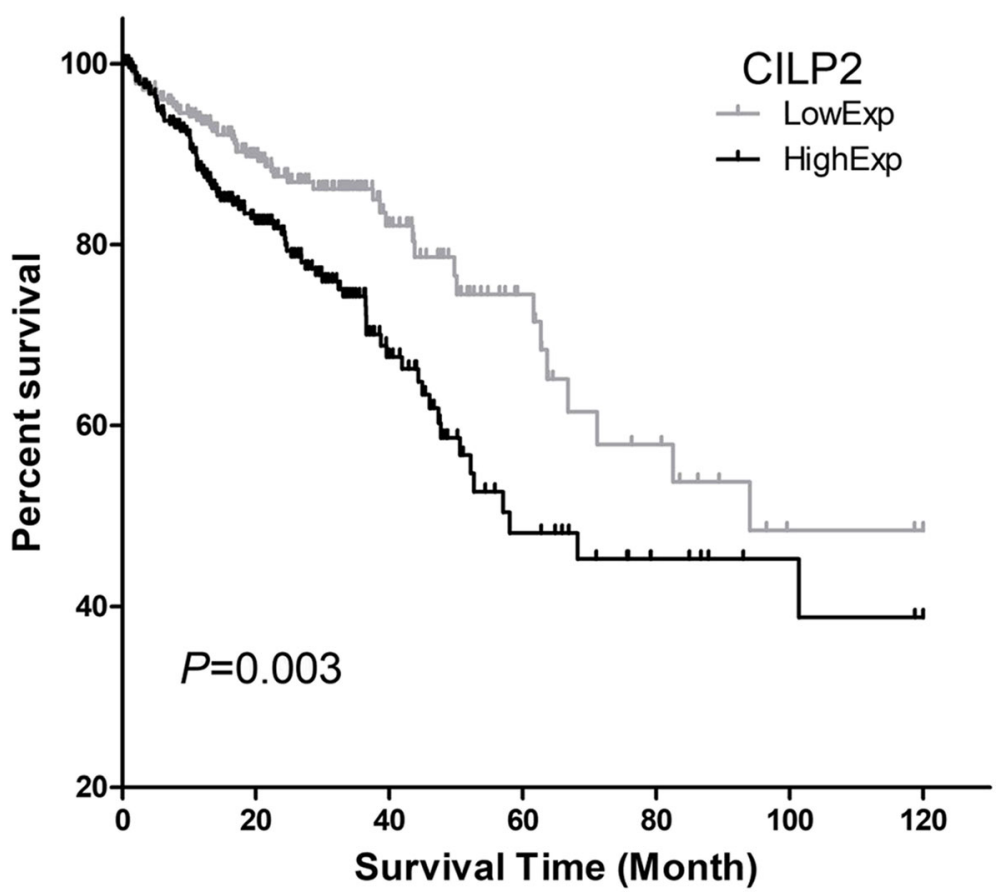

Fig. 3 The Kaplan-Meier analysis of CILP2 expression and overall survival in total CRC samples of 10 years in TCGA cohort. Higher CILP2 expression group had a poorer overall survival than the low CILP2 expression group $(P=0.003)$

\section{Discussion}

The incidence of CRC has risen sharply in recent years [1], with limited diagnostic and prognostic tools for early detection and patients' survival prediction. Many researches are focusing on the issue, and numerous advances have been achieved to reveal the underlying mechanisms of cancer development [4-7]. For example, lots of studies have shown that microsatellite instability (MSI) in the genome could act as an exclusive prognostic marker in the early stages of CRC $[4,20]$. Another useful tool, Septin9 hypermethylation detection in blood samples, has received researchers' attention and was the first-approved serum test for CRC screening by FDA. But further estimation on Septin9 serum assay for CRC screening turned out that it was weakly recommended because of low sensitivity for cancer and inability to detect advanced adenomas [21]. Extensive works are still needed to provide new insights into the tumor.

CILP2 is a noncollagenous protein in human articular cartilage. In the last few years, correlations between CILP2 and plasma lipid concentration in different populations have been studied in some GWAS researches. According to Kathiresan et al. [9], in Caucasian individuals analyzed, rs16996148 variant of CILP2 gene had a reducing role in triglyceride and LDL-C level. Rašlová et al.'s report on the association between CILP2 polymorphism and FER(HDL) supports its role in lipid metabolism [22], while in other reports, the relationship between CILP2 polymorphism and lipid metabolism was not yet discovered [23], nor in the Japanese population [24] or Slovak Midlife women [25]. However, Luptáková et al. indicated that the minor $\mathrm{T}$ allele in the CILP2 gene was associated with lower LDL-C, apoB, and atherogenic indices and higher HDL-C levels [25]. This result was by the study in the Singaporean population ranging from 40 to 80 years of age [26]. On the other hand, it has been reported that SNPs in CILP2 gene were associated with adult height attainment [27], and CpGs in CILP2 were statistically significantly associated with both body mass index and fat-free mass index in preschool children [28]. In summary, most of the current reports suggest the correlation between CLIP2 and lipid metabolism. However, the molecular mechanism on CLIP2 affecting lipid metabolism is still unclear. According to Zhang et al., an expression quantitative trait locus for the CILP2 gene, rs8103992, was statistically significantly associated with adult height attainment and osteosarcoma risk after adjustment for multiple comparisons in 864 osteosarcoma cases and 1879 controls of European ancestry [16]. To our best knowledge, no more reports were describing the relationship between CILP2 and cancers. 
Table 4 Survival analysis was performed by the Kaplan-Meier method

\begin{tabular}{|c|c|c|c|c|c|c|}
\hline \multicolumn{2}{|l|}{ Variables } & \multirow{2}{*}{$\frac{N}{304}$} & \multirow{2}{*}{$\begin{array}{l}\text { Means for survival time (month) } \\
83.770\end{array}$} & \multicolumn{2}{|c|}{ Survival time (month, $95 \% \mathrm{Cl}$ ) } & \multirow{2}{*}{$\frac{P \text { value }}{0.003}$} \\
\hline CILP2 expression & Low & & & 74.181 & 93.359 & \\
\hline & High & 305 & 70.805 & 61.802 & 79.807 & \\
\hline & Total & 609 & 77.193 & 70.583 & 83.803 & \\
\hline \multirow[t]{3}{*}{ Gender } & Male & 329 & 74.017 & 64.871 & 83.163 & 0.941 \\
\hline & Female & 280 & 80.242 & 70.918 & 89.566 & \\
\hline & Total & 609 & 77.193 & 70.583 & 83.803 & \\
\hline \multirow[t]{3}{*}{ Age } & $\leq 68$ & 324 & 86.777 & 77.219 & 96.334 & $<0.0001$ \\
\hline & $>68$ & 285 & 68.173 & 59.326 & 77.021 & \\
\hline & Total & 609 & 77.193 & 70.583 & 83.803 & \\
\hline \multirow[t]{3}{*}{ T stage } & $\mathrm{T} 1 / 2$ & 126 & 97.409 & 81.150 & 113.667 & 0.003 \\
\hline & $\mathrm{T} 3 / 4$ & 481 & 74.489 & 67.519 & 81.460 & \\
\hline & Total & 607 & 77.572 & 70.950 & 84.194 & \\
\hline \multirow[t]{3}{*}{$N$ stage } & No & 348 & 88.348 & 79.810 & 96.887 & $<0.0001$ \\
\hline & $\mathrm{N} 1 / 2 / 3$ & 257 & 63.017 & 53.234 & 72.799 & \\
\hline & Total & 605 & 77.530 & 70.908 & 84.152 & \\
\hline \multirow[t]{3}{*}{ M stage } & Mo & 450 & 87.130 & 79.689 & 94.571 & $<0.0001$ \\
\hline & M1 & 86 & 37.131 & 29.468 & 44.794 & \\
\hline & Total & 536 & 78.778 & 71.809 & 85.747 & \\
\hline \multirow[t]{3}{*}{ Clinical stage } & Stage I/II & 330 & 89.089 & 80.335 & 97.843 & $<0.0001$ \\
\hline & Stage III/IV & 262 & 64.632 & 54.851 & 74.413 & \\
\hline & Total & 592 & 78.325 & 71.646 & 85.005 & \\
\hline
\end{tabular}

$P$ value $<0.05$ was considered statistically significant (in bold). $T$ tumor, $N$ regional lymph node, $M$ metastasis

Our work presented here has evaluated the prognostic value of CILP2 in CRC by analyzing a dataset of TCGA cohort and TMA cohort. For the first time, we found out that CILP2 was upregulated in tumor tissues compared to normal tissues. Also, we observed that CILP2 expression was statistically significantly correlated with clinicopathological parameters of CRC patients in TCGA cohort and TMA cohort. In high-stage CRC samples, CILP2 was upregulated compared to low-stage CRC samples. To evaluate the prognostic value of CILP2 on the overall survival of CRC patients in TCGA cohort, the Kaplan-Meier and Cox regression analyses were performed. We found out that higher CILP2 expression was correlated with a much poorer prognosis in the patients. These results indicated that CILP2 could act as an independent prognostic marker in CRC.

Recently, many reports have shown that obesity represents a common risk factor for several types of cancer $[29,30]$, especially for hormone-dependent cancers, such as breast cancer [31, 32] and advanced prostate cancer [33]. The biological association between obesity and cancer might relate to tissue lipid metabolism. It is well

Table 5 Survival analysis was performed by univariate and multivariate Cox regression analysis

\begin{tabular}{|c|c|c|c|c|c|c|}
\hline \multirow[t]{2}{*}{ Variables } & \multicolumn{3}{|c|}{ Univariate analysis } & \multicolumn{3}{|c|}{ Multivariate analysis } \\
\hline & $P$ value & $\mathrm{HR}$ & $95 \% \mathrm{Cl}$ & $P$ value & HR & $95 \% \mathrm{Cl}$ \\
\hline CILP2 expression (high vs. low) & 0.003 & 1.713 & $1.194-2.457$ & 0.034 & 1.547 & $1.033-2.317$ \\
\hline Gender (male vs. female) & 0.941 & 0.987 & $0.694-1.404$ & 0.132 & 1.351 & $0.913-1.999$ \\
\hline Age (> 68 vs. $\leq 68)$ & $<0.0001$ & 1.923 & $1.337-2.767$ & $<0.0001$ & 2.626 & $1.743-3.957$ \\
\hline T stage (T3/4 vs. T1/2) & 0.005 & 2.457 & $1.320-4.572$ & 0.143 & 1.817 & $0.816-4.044$ \\
\hline N stage (N1/2/3 vs. N0) & $<0.0001$ & 2.734 & $1.897-3.942$ & 0.264 & 0.589 & $0.232-1.491$ \\
\hline M stage (M1 vs. M0) & $<0.0001$ & 4.126 & $2.776-6.133$ & $<0.0001$ & 2.854 & $1.769-4.604$ \\
\hline Clinical stage (III/IV vs. I/II) & $<0.0001$ & 3. & $2.046-4.401$ & 0.017 & 3.408 & $1.244-9.337$ \\
\hline
\end{tabular}

$P$ value $<0.05$ was considered statistically significant (in bold). $T$ tumor, $N$ regional lymph node, $M$ metastasis, $H R$ hazard ratio, $C l$ confidence interval 
known that cancer cells, including CRC cells, show alterations in lipid metabolism of synthesis, desaturation, elongation, and mitochondrial oxidation of fatty acids [34-36]. A population-based study has revealed incidences of CRC to be associated with circulating levels of apolipoproteins [35]. However, there have been no reports on the specific molecular mechanism by which CLIP2 gene affects lipid metabolism, and sophisticated correlation and therapeutic use of lipid metabolismrelated alternations remain further investigations.

\section{Conclusions}

Our study has raised that CILP2 might serve as a potential prognostic marker in CRC patients. Further studies would be needed to detect CILP2 expression in serum of the patients and confirm the prognostic value and feasibility in larger and multi-center cohorts of the patients, as well as to further elucidate molecular mechanisms underlying correlations between CILP2, lipid metabolism, and CRC development.

\begin{abstract}
Abbreviations
CILP2: Cartilage intermediate layer protein 2; TCGA: The Cancer Genome Altas; TMA: Tissue microarray; OS: Overall survival; CRC: Colorectal cancer; GWAS: Genome-wide association studies; NCAN-CILP2-PBX4: Neurocancartilage intermediate layer protein 2-pre-B cell leukemia homeobox 4; NAFL D: Non-alcoholic fatty liver disease; MSI: Microsatellite instability; SNPs: Single nucleotide polymorphisms; LDL-C: Low-density lipoprotein cholesterol; HDLC: High-density lipoprotein cholesterol
\end{abstract}

\section{Acknowledgements}

The study was sponsored by Fujian Provincial Health Technology Project.

\section{Authors' contributions}

Qing Ye designed the study. Feng Huang and Yuanfei Peng collected the data and carried out the experiment. Jinhu Chen, Yangming Li, and Shengyuan Liu performed the statistical analyses. Yangmei Xu and Lijie Huang took responsibility for the histology and immunohistochemistry. Feng Huang and Qing Ye wrote the manuscript. Qing Ye took responsibility for obtaining permission from all co-authors for the submission of any version of the paper and any changes in authorship. All authors read and approved the final manuscript.

\section{Funding}

The study was funded by the Natural Science Foundation of Fujian Province (grant number: 2019J01195) and Fujian Provincial Health and Family Planning Research Talent Training Program (grant number: 2019-ZQN-15),

\section{Availability of data and materials}

The datasets used and/or analyzed during the current study are available from the corresponding author upon reasonable request.

\section{Ethics approval and consent to participate}

Not applicable.

\section{Consent for publication}

Not applicable.

\section{Competing interests}

The authors declare that they have no competing interests.

\section{Author details}

'Department of Gastrointestinal Tumor Surgery, Fujian Cancer Hospital \& Fujian Medical University Cancer Hospital, Fujian Province Key Laboratory of Tumor Biotherapy, No. 420 Fuma Road, Fuzhou ,350014, Fujian Province,
People's Republic of China. ${ }^{2}$ Department of Liver Surgery, Liver Cancer Institute, Zhongshan Hospital, Fudan University, Key Laboratory of Carcinogenesis and Cancer Invasion of Ministry of Education, Shanghai 200032, People's Republic of China.

Received: 13 April 2020 Accepted: 14 October 2020

Published online: 24 October 2020

\section{References}

1. Bray F, Ferlay J, Soerjomataram I, Siegel RL, Torre LA, Jemal A. Global cancer statistics 2018: GLOBOCAN estimates of incidence and mortality worldwide for 36 cancers in 185 countries. CA Cancer J Clin. 2018;68(6):394-424.

2. Grady WM, Carethers JM. Genomic and epigenetic instability in colorectal cancer pathogenesis. Gastroenterology. 2008;135(4):1079-99.

3. O'Connell MJ, Campbell ME, Goldberg RM, Grothey A, Seitz JF, Benedetti JK, André T, Haller DG, Sargent DJ. Survival following recurrence in stage II and III colon cancer: findings from the ACCENT data set. J Clin Oncol. 2008; 26(14):2336-41.

4. Guastadisegni C, Colafranceschi M, Ottini L, Dogliotti E. Microsatellite instability as a marker of prognosis and response to therapy: a meta-analysis of colorectal cancer survival data. Eur J Cancer. 2010;46(15):2788-98,

5. Lansdorp-Vogelaar I, Knudsen AB, Brenner H. Cost-effectiveness of colorectal cancer screening. Epidemiol Rev. 2011;33:88-100.

6. Parsons MT, Buchanan DD, Thompson B, Young JP, Spurdle AB. Correlation of tumour BRAF mutations and MLH1 methylation with germline mismatch repair (MMR) gene mutation status: a literature review assessing utility of tumour features for MMR variant classification. J Med Genet. 2012;49(3):151-7.

7. Merlos-Suárez A, Barriga FM, Jung P, Iglesias M, Céspedes MV, Rossell D, Sevillano M, Hernando-Momblona X, da Silva-Diz V, Muñoz P, Clevers H, Sancho E, Mangues R, Batlle E. The intestinal stem cell signature identifies colorectal cancer stem cells and predicts disease relapse. Cell Stem Cell. 2011:8(5):511-24.

8. Valdes AM, Hart DJ, Jones KA, Surdulescu G, Swarbrick P, Doyle DV, Schafer $\mathrm{AJ}$, Spector TD. Association study of candidate genes for the prevalence and progression of knee osteoarthritis. Arthritis Rheum. 2004;50(8):2497-507.

9. Kathiresan S, Melander O, Guiducci C, Surti A, Burtt NP, Rieder MJ, Cooper GM, Roos C, Voight BF, Havulinna AS, Wahlstrand B, Hedner T, Corella D, Tai ES, Ordovas JM, Berglund G, Vartiainen E, Jousilahti P, Hedblad B, Taskinen MR, Newton-Cheh C, Salomaa V, Peltonen L, Groop L, Altshuler DM, OrhoMelander M. Six new loci associated with blood low-density lipoprotein cholesterol, high-density lipoprotein cholesterol or triglycerides in humans. Nat Genet. 2008:40(2):189-97.

10. Waterworth DM, Ricketts SL, Song K, et al. Genetic variants influencing circulating lipid levels and risk of coronary artery disease. Arterioscler Thromb Vasc Biol. 2010;30(11):2264-76.

11. Keebler ME, Deo RC, Surti A, Konieczkowski D, Guiducci C, Burtt N, Buxbaum SG, Sarpong DF, Steffes MW, Wilson JG, Taylor HA, Kathiresan S. Finemapping in African Americans of 8 recently discovered genetic loci for plasma lipids: the Jackson Heart Study. Circ Cardiovasc Genet. 2010;3(4): 358-64.

12. Yan $T$, Yin $R X$, Li $Q$, Huang $P$, Zeng XN, Huang KK, Aung LH, Wu DF, Liu CW, Pan SL. Sex-specific association of rs16996148 SNP in the NCAN/CILP2/ PBX4 and serum lipid levels in the Mulao and Han populations. Lipids Health Dis. 2011:10:248.

13. Speliotes EK, Yerges-Armstrong LM, Wu J, et al. Genome-wide association analysis identifies variants associated with nonalcoholic fatty liver disease that have distinct effects on metabolic traits. PLoS Genet. 2011;7(3): e1001324.

14. Kitamoto T, Kitamoto A, Yoneda M, Hyogo H, Ochi H, Nakamura T, Teranishi H, Mizusawa S, Ueno T, Chayama K, Nakajima A, Nakao K, Sekine A, Hotta K. Genome-wide scan revealed that polymorphisms in the PNPLA3, SAMM50, and PARVB genes are associated with development and progression of nonalcoholic fatty liver disease in Japan. Hum Genet. 2013;132(7):783-92.

15. Wang C, Li P, Xuan J, Zhu C, Liu J, Shan L, Du Q, Ren Y, Ye J. Cholesterol enhances colorectal cancer progression via ros elevation and mapk signaling pathway activation. Cell Physiol Biochem. 2017;42(2):729-42.

16. Zhang C, Morimoto LM, de Smith AJ, Hansen HM, Gonzalez-Maya J, Endicott AA, Smirnov IV, Metayer C, Wei Q, Eward WC, Wiemels JL, Walsh KM. Genetic determinants of childhood and adult height associated with osteosarcoma risk. Cancer. 2018;124(18):3742-52. 
17. Ye Q, Wang TF, Peng YF, Xie J, Feng B, Qiu MY, Li LH, Lu AG, Liu BY, Zheng $\mathrm{MH}$. Expression of $\alpha-$-, $\beta$ - and $\gamma$-synuclein in colorectal cancer, and potential clinical significance in progression of the disease. Oncol Rep. 2010;23(2): 429-36.

18. Zhao Y, Cui WL, Feng ZY, Xue J, Gulinaer A, Zhang W. Expression of Foxp3 and interleukin-7 receptor and clinicopathological characteristics of patients with diffuse large B-cell lymphoma. Oncol Lett. 2020;19(4):2755-64.

19. Jiang FN, Dai LJ, Yang SB, Wu YD, Liang YX, Yin XL, Zou CY, Zhong WD. Increasing of FKBP9 can predict poor prognosis in patients with prostate cancer. Pathol Res Pract. 2020:216(1):152732.

20. Hutchins G, Southward K, Handley K, Magill L, Beaumont C, Stahlschmidt J, Richman S, Chambers P, Seymour M, Kerr D, Gray R, Quirke P. Value of mismatch repair, KRAS, and BRAF mutations in predicting recurrence and benefits from chemotherapy in colorectal cancer. J Clin Oncol. 2011;29(10): 1261-70.

21. Rex DK, Boland CR, Dominitz JA, Giardiello FM, Johnson DA, Kaltenbach T, Levin TR, Lieberman D, Robertson DJ. Colorectal cancer screening: recommendations for physicians and patients from the U.S. Multi-Society Task Force on Colorectal Cancer. Gastroenterology. 2017;153(1):307-23.

22. Rašlová $K$, Dobiášová $M$, Hubáček JA, Bencová $D$, Siváková $D$, Danková $Z$, Franeková J, Jabor A, Gašparovič J, Vohnout B. Association of metabolic and genetic factors with cholesterol esterification rate in HDL plasma and atherogenic index of plasma in a 40 years old Slovak population. Physiol Res. 2011; 60(5):785-795.

23. Járomi L, Csöngei V, Polgár N, Rappai G, Szolnoki Z, Maász A, Horvatovich K, Sáfrány E, Sipeky C, Magyari L, Melegh B. Triglyceride level-influencing functional variants of the ANGPTL3, CILP2, and TRIB1 loci in ischemic stroke. Neuromolecular Med. 2011;13(3):179-86.

24. Nakayama K, Bayasgalan T, Yamanaka K, Kumada M, Gotoh T, Utsumi N, Yanagisawa Y, Okayama M, Kajii E, Ishibashi S, Iwamoto S; Jichi Community Genetics Team (JCOG). Large scale replication analysis of loci associated with lipid concentrations in a Japanese population. . J Med Genet. 2009; 46(6):370-374.

25. Luptáková L, Benčová D, Siváková D, Cvíčelová M. Association of CILP2 and ACE gene polymorphisms with cardiovascular risk factors in Slovak midlife women. Biomed Res Int. 2013;2013:634207.

26. Tai ES, Sim XL, Ong TH, Wong TY, Saw SM, Aung T, Kathiresan S, OrhoMelander M, Ordovas JM, Tan JT, Seielstad M. Polymorphisms at newly identified lipid-associated loci are associated with blood lipids and cardiovascular disease in an Asian Malay population. J Lipid Res. 2009;50(3): 514-20.

27. Wood AR, Esko T, Yang J, et al. Defining the role of common variation in the genomic and biological architecture of adult human height. Nat Genet. 2014;46(11):1173-86.

28. Rzehak P, Covic M, Saffery R, Reischl E, Wahl S, Grote V, Weber M, Xhonneux A, Langhendries JP, Ferre N, Closa-Monasterolo R, Escribano J, Verduci E, Riva E, Socha P, Gruszfeld D, Koletzko B. DNA-methylation and body composition in preschool children: epigenome-wide-analysis in the European Childhood Obesity Project (CHOP)-Study. Sci Rep. 2017;7(1):14349.

29. Renehan AG, Tyson M, Egger M, Heller RF, Zwahlen M. Body-mass index and incidence of cancer: a systematic review and meta-analysis of prospective observational studies. Lancet. 2008;371(9612):569-78.

30. Vainio $H$, Kaaks $R$, Bianchini $F$. Weight control and physical activity in cancer prevention: international evaluation of the evidence. Eur J Cancer Prev. 2002;11(Suppl 2):S94-100.

31. Vrieling A, Buck K, Kaaks R, Chang-Claude J. Adult weight gain in relation to breast cancer risk by estrogen and progesterone receptor status: a metaanalysis. Breast Cancer Res Treat. 2010;123(3):641-9.

32. Howell A, Anderson AS, Clarke RB, Duffy SW, Evans DG, Garcia-Closas M, Gescher AJ, Key TJ, Saxton JM, Harvie MN. Risk determination and prevention of breast cancer. Breast Cancer Res. 2014;16(5):446.

33. Møller H, Roswall N, Van Hemelrijck M, Larsen SB, Cuzick J, Holmberg L, Overvad K, Tjønneland A. Prostate cancer incidence, clinical stage and survival in relation to obesity: a prospective cohort study in Denmark. Int $J$ Cancer. 2015;136(8):1940-7.

34. Pakiet A, Kobiela J, Stepnowski P, Sledzinski T, Mika A. Changes in lipids composition and metabolism in colorectal cancer: a review. Lipids Health Dis. 2019;18(1):29.

35. Borgquist $S$, Butt T, Almgren $P$, Shiffman D, Stocks T, Orho-Melander M, Manjer J, Melander O. Apolipoproteins, lipids and risk of cancer. Int J Cancer. 2016;138(11):2648-56.
36. Ackerman D, Simon MC. Hypoxia, lipids, and cancer: surviving the harsh tumor microenvironment. Trends Cell Biol. 2014;24(8):472-8.

\section{Publisher's Note}

Springer Nature remains neutral with regard to jurisdictional claims in published maps and institutional affiliations.

\section{Ready to submit your research? Choose BMC and benefit from:}

- fast, convenient online submission

- thorough peer review by experienced researchers in your field

- rapid publication on acceptance

- support for research data, including large and complex data types

- gold Open Access which fosters wider collaboration and increased citations

- maximum visibility for your research: over $100 \mathrm{M}$ website views per year

At BMC, research is always in progress.

Learn more biomedcentral.com/submissions 